Revista Destaques Acadêmicos, Lajeado, v. 11, n. 4, 2019. ISSN 2176-3070

DOI: http://dx.doi.org/10.22410/issn.2176-3070.v11i4a2019.2280

http://www.univates.br/revistas

\title{
MÉTODOS PARA A DETERMINAÇÃO DE VITAMINA C EM DIFERENTES AMOSTRAS
}

\author{
Lucélia Hoehne, Luana Gabriela Marmitt
}

Resumo: A vitamina C, ou ácido ascórbico, pode ser encontrada naturalmente em frutas, vegetais, tecidos animais e produtos derivados. Também é adicionada pelas indústrias em fármacos e alimentos. No organismo é responsável por diversas funções, porém, não é sintetizada pelos humanos, tornando necessária sua ingestão através da dieta. No entanto, a vitamina é uma das mais sensíveis às etapas de processamento e armazenamento de produtos. Portanto, a sua retenção é considerada como um índice de conservação destes. Em virtude de sua grande importância e vasta utilização, a análise de alimentos, bebidas, amostras biológicas e produtos farmacêuticos é de grande relevância e, assim, diversos métodos foram desenvolvidos para sua determinação. Atualmente, os mais utilizados são os físico-químicos, dentre os quais encontram-se titulométricos e espectrofotométricos. Estes, por serem mais simples, rápidos e não necessitarem de reagentes ou equipamentos sofisticados, estão entre os mais frequentemente empregados. Desta forma, considerando a importância da vitamina $C$, o objetivo deste trabalho consiste em apresentar uma revisão de métodos com menor custo para a sua quantificação em diferentes tipos de amostras, destacando o princípio, interferentes, vantagens e desvantagens que apresentam. Técnicas tradicionais continuam sendo bastante empregadas, mesmo com o desenvolvimento de metodologias mais recentes. Os procedimentos titulométricos são mais comumente utilizados na análise de fármacos, produtos alimentícios e bebidas, enquanto que espectrofotométricos, além destas amostras, também possibilitam a determinação da vitamina $\mathrm{C}$ em fluídos biológicos. E, devido ao baixo custo e praticidade que possuem, tais métodos ainda são de grande interesse.

Palavras-chave: Vitamina C. Métodos. Alimentos. Amostras biológicas. Produtos farmacêuticos.

\section{INTRODUÇÃO}

O ácido ascórbico, ou vitamina $\mathrm{C}$, é encontrado naturalmente em frutas, vegetais e em menor teor nos tecidos animais e produtos derivados (DAMODARAN; PARKIN; FENNEMA, 2010). Além disso, é adicionado em alimentos e produtos farmacêuticos pelas indústrias, tanto como ingrediente principal, quanto como estabilizante de demais nutrientes e antioxidante. No organismo também possui função antioxidante, sendo importante para 
diversas funções (ARYA; MAHAJAN; JAIN, 1998; CRUZ; LOBATO; SANTOS, 2013). Porém, não é sintetizada pelos humanos, devendo ser adquirida através da dieta (PENTEADO, 2003).

A vitamina $C$ é uma das mais sensíveis ao processamento e condições de armazenamento dos produtos, podendo sofrer significativa degradação durante esses períodos. Assim, a sua retenção é considerada como um índice de conservação de alimentos e da qualidade nutricional (DAMODARAN; PARKIN; FENNEMA, 2010; ROSA et al., 2007; SUCUPIRA; XEREZ; SOUSA, 2012).

Devido à grande importância da vitamina e sua vasta utilização, a análise de alimentos, bebidas, fluídos biológicos e produtos farmacêuticos possui grande relevância. Desta forma, diversos métodos para a sua quantificação foram desenvolvidos. Dentre estes, encontram-se titulométricos, eletroquímicos, luminescentes, fluorimétricos, cromatográficos e espectrofotométricos. Além disso, metodologias elaboradas também visam uma análise mais rápida, simples, precisa, com boa sensibilidade e seletividade e com menor uso de reagentes (ARYA; MAHAJAN; JAIN, 1998, 2000; ARYA; MAHJAN, 1996; LIMA et al., 2007; QUINÁIA; FERREIRA, 2007).

A seleção do método analítico apropriado é fundamental para atingir resultados precisos. Técnicas tradicionais se baseiam na titulação de oxirredução da amostra (DAMODARAN; PARKIN; FENNEMA, 2010). Métodos espectrofotométricos, assim como titulométricos, apresentam praticidade, rapidez, simplicidade e possuem baixo custo, não necessitando equipamentos e reagentes sofisticados. Portanto, devido à tais vantagens, estes métodos estão entre os mais comumente utilizados (DA SILVA et al., 2019; SPÍNOLA, 2011).

Assim, considerando a importância e o grande uso da vitamina $C$, este artigo tem como objetivo apresentar uma revisão sobre métodos que possuem menor custo desenvolvidos para sua quantificação, destacando o princípio no qual se baseiam, interferentes encontrados, as amostras aos quais podem ser aplicados, bem como vantagens e desvantagens que apresentam.

\section{DESENVOLVIMENTO}

\subsection{A vitamina $C$}

O termo vitamina $\mathrm{C}$ é utilizado para descrever de forma genérica todos os compostos que possuem a atividade biológica do ácido ascórbico, sendo que o composto natural principal com essa atividade é o ácido L-ascórbico (PENTEADO, 2003).

Ela é classificada como hidrossolúvel e pode ser encontrada em alimentos e na natureza na forma de ácido ascórbico e na sua forma oxidada, ácido dehidroascórbico. Ambas possuem função fisiológica, porém, mais uma oxidação do ácido dehidroascórbico leva à formação de ácido dicetogulônico, 
acarretando na inativação irreversível da vitamina e perda de sua atividade biológica (BARCIA et al., 2010; CRUZ; LOBATO; SANTOS, 2013; SUCUPIRA; XEREZ; SOUSA, 2012). A reação ocorre por meio da abertura do anel lactona através da hidrólise (DAMODARAN; PARKIN; FENNEMA, 2010; PENTEADO, 2003). A oxidação do ácido está representada na Figura 1.

Figura 1 - Oxidação do ácido ascórbico a ácido dehidroascórbico e ácido dicetogulônico

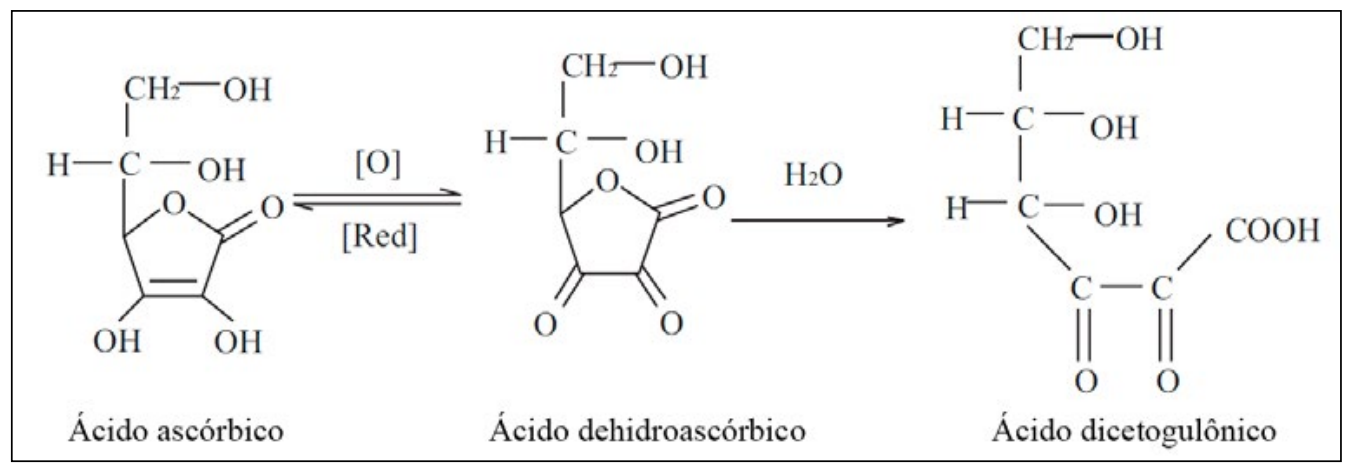

Fonte: Da autora, adaptado de Sucupira; Xerez; Sousa (2012).

A vitamina é um forte agente redutor e se oxida com facilidade. A sua degradação pode ser influenciada por diversos fatores como luz, oxigênio, catalisadores metálicos, temperatura, umidade ou atividade de água e $\mathrm{pH}$, possuindo oxidação mais rápida em meio alcalino e razoável estabilidade em soluções levemente ácidas (DA SILVA; MARTINS; DEUS, 2009; DE ANDRADE et al., 2002; EL-ISHAQ; OBIRINAKEM, 2015; SUCUPIRA; XEREZ; SOUSA, 2012).

O composto é fundamental para a saúde, possuindo importante papel no desenvolvimento e regeneração de músculos, pele, ossos, dentes, formação e manutenção do colágeno, regulação da temperatura corporal, produção de hormônios e metabolismo geral (DE ANDRADE et al., 2002; PENTEADO, 2003). Por ser um poderoso antioxidante, a vitamina $C$ pode proteger o organismo contra doenças crônicas como câncer, catarata e doenças cardiovasculares (MUNYAKA et al., 2010). Também é importante pois captura radicais livres, atua no transporte de elétrons e auxilia na absorção de ferro no intestino (FIORUCCI; SOARES; CAVALHEIRO, 2003).

\subsection{Métodos}

São diversas as técnicas que possibilitam a identificação e quantificação da vitamina C. Atualmente, as mais utilizadas são as físico-químicas (DE OLIVEIRA; GODOY; PRADO, 2010; PENTEADO, 2003). Dentre estas, encontram-se as volumétricas e instrumentais, sendo que geralmente as 
propriedades de redução do ácido ascórbico são o princípio dos procedimentos para sua determinação (BAZEL; RIABUKHINA; TIRPÁK, 2018; TAVARES et al., 1999). Todos os métodos possuem vantagens e desvantagens que precisam ser avaliadas. Dependendo da amostra, a detecção da vitamina $C$ pode ser um desafio em função de estar presente em baixos teores, às suas diversas formas químicas e ser bastante instável sob diferentes condições. Ainda, interferentes existentes na matriz analisada podem afetar a análise do ácido ascórbico e contribuir para sua degradação (SPÍNOLA, 2011).

Devido às variadas composições, características, propriedades de extração e purificação de cada amostra, o mesmo método nem sempre pode ser utilizado para amostras de diferentes tipos. Além disso, nem todas as técnicas possibilitam a quantificação da vitamina $C$ total (ácido ascórbico e dehidroascórbico) devido às suas distintas propriedades químicas, eletroquímicas e ópticas (MOHAMMED; HAMAD; MOHAMMED, 2009). Portanto, a escolha da metodologia deve levar em conta a matriz, possíveis interferentes e recursos analíticos disponíveis (SPÍNOLA, 2011).

A partir da revisão de literatura, a seguir estão apresentados métodos titulométricos e espectrofotométricos.

\subsubsection{Titulométricos}

Titulações consistem em procedimentos quantitativos que têm como base a medida da quantidade consumida de um reagente, que possui uma concentração conhecida, por um analito durante uma reação química ou eletroquímica (SKOOG et al., 2015). Os métodos titulométricos são bastante comuns e utilizam diversos agentes oxidantes para a análise do ácido ascórbico, tendo como base o forte poder redutor da vitamina (SPÍNOLA, 2011; TAVARES, et al. 1999).

\subsubsection{Método de Tillmans}

Consiste em um método colorimétrico que se baseia na redução do corante 2,6-diclorofenolindofenol (DCFI), que é o reativo de Tillmans preparado com bicarbonato de sódio, através de uma solução ácida da vitamina, contendo ácido metafosfórico e ácido acético. O ponto de viragem da titulação é determinado pela mudança de cor do DCFI de azul, em meio alcalino, para rosa, em meio ácido (ALDRIGUE, 1998; IAL, 2008; LIMA et al., 2007). O ácido ascórbico reduz o DCFI a uma solução incolor, e, ao fim da titulação, o excesso do indicador que não foi reduzido, origina a coloração rosa na solução ácida (DE OLIVEIRA; GODOY; PRADO, 2010). A reação entre o DCFI e o ácido ascórbico está representada na Figura 2. O ponto final também pode ser avaliado pela sua absorbância a 518 nm (EITENMILLER; YE; JUNIOR, 2008). 
Figura 2 - Reação do DCFI com o ácido ascórbico

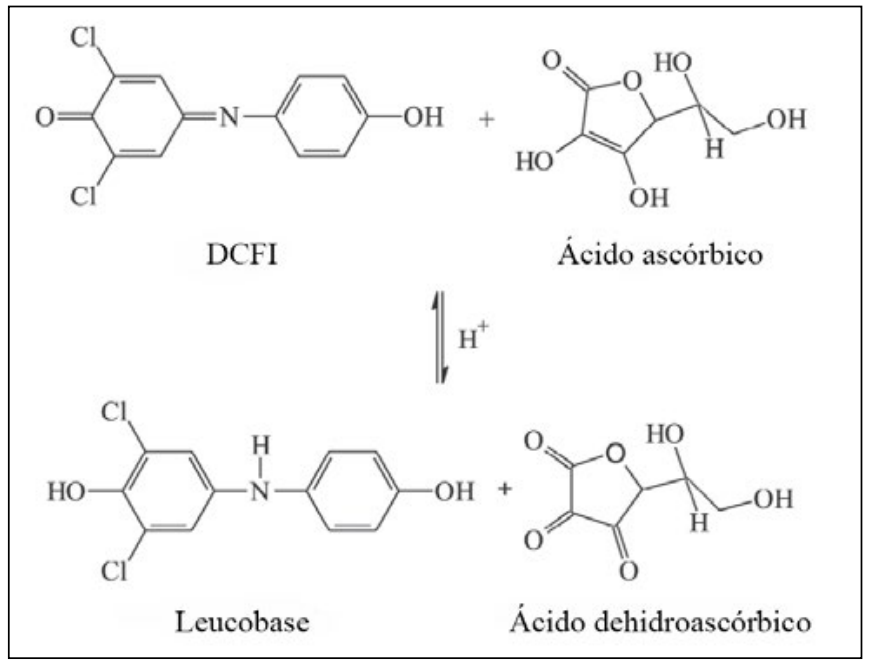

Fonte: Da autora, adaptado de Lima et al. (2007).

O método pode ser utilizado em amostras que contenham baixa concentração de vitamina, como sucos de frutas. Porém, diversos compostos podem atuar como interferentes, como íons de ferro, cobre e estanho, pigmentos, taninos, cisteína, metabissulfito e demais substâncias redutoras. A presença de íons interferentes pode ser checada através de teste com solução de azul de metileno ou índigo carmim. O procedimento também possui limitações em soluções coloridas, além de ter pouca especificidade, instabilidade de cor e não determinar o ácido dehidroascórbico (ALDRIGUE, 1998; IAL, 2008; SPÍNOLA, 2011).

Assim, a sua aplicação é mais restrita a frutas cítricas e tabletes de multivitamina, que não possuem minerais em sua composição (LIMA et al., 2007). Ainda, o reagente de Tillmans deve ser padronizado sempre que for utilizado com solução de vitamina C recentemente preparada (IAL, 2008). Para minimizar o efeito de interferentes, a titulação deve ser realizada rapidamente e em meio fortemente ácido (PENTEADO, 2003). Apesar disso, a técnica é de fácil aplicação e possui baixo custo, sendo ainda empregada como base na comparação para novas metodologias desenvolvidas. A utilização do DCFI é bastante frequente, não só para produtos alimentícios, mas também para fármacos (DE OLIVEIRA; GODOY; PRADO, 2010).

De Oliveira, Godoy e Prado (2010) desenvolveram uma otimização do método para amostras que apresentam coloração. Os autores analisaram geleias de frutas e modificações incluem etapas de extração com ultrassom e centrifugação. A amostra foi utilizada como titulante e o DCFI juntamente com água destilada foi titulado. Dentre as vantagens descritas, além da análise de 
amostras pigmentadas, estão o menor uso do reagente DCFI e menor geração de resíduos em comparação ao método oficial. Outra modificação para amostras com coloração e também para a análise de vitamina $C$ total, consiste na prévia utilização de extração em fase sólida para remoção de compostos coloridos e interferentes. A redução do ácido dehidroascórbico é realizada com cloridrado de cisteína (VERMA et al., 1996).

\subsubsection{Titulação com iodato de potássio}

O método tem seu princípio na oxidação da vitamina $C$ pela titulação com iodato de potássio, em meio acidificado com ácido sulfúrico e na presença de iodeto de potássio e solução de amido (IAL, 2008). Quando a solução é titulada, devido a interação entre o iodato e iodeto forma-se o iodo (REAÇÃO 1), que realiza a oxidação do ácido ascórbico (REAÇÃO 2). Após toda vitamina ser consumida, o iodo gerado reage com o amido e origina um complexo de coloração azul (DA SILVA et al., 2019; MUSSA; SHARAA, 2014; TAVARES et al., 1999; VOGEL, 2013).

$$
\begin{aligned}
& \mathrm{KIO}_{3}+5 \mathrm{I}^{-}+6 \mathrm{H}^{+} \rightarrow 3 \mathrm{I}_{2}+3 \mathrm{H}_{2} \mathrm{O}+\mathrm{K}^{+} \\
& \mathrm{C}_{6} \mathrm{H}_{8} \mathrm{O}_{6}+\mathrm{I}_{2} \rightarrow \mathrm{C}_{6} \mathrm{H}_{6} \mathrm{O}_{6}+2 \mathrm{I}^{-}+2 \mathrm{H}^{+}
\end{aligned}
$$

A técnica pode ser utilizada em alimentos enriquecidos e in natura, quando o teor de ácido ascórbico for superior a $5 \mathrm{mg}$ (IAL, 2008). Uma de suas vantagens é o baixo custo do amido. Além disso, a solução de iodato é muito estável em comparação à de Tillmans, que precisa de verificação diariamente (TAVARES et al., 1999; VILLELA; PECCI, 1943). Porém, com este método também não é possível quantificar diretamente o teor de ácido dehidroascórbico (SPÍNOLA, 2011). O procedimento ainda pode ser realizado de forma na qual o iodo gerado em excesso é titulado com tiossulfato de sódio ou adicionando apenas amido na amostra e executando a titulação com iodo, podendo ser analisados suplementos, frutas e vegetais (DA SILVA, 2019; MAJIDI; Y-ALQUBURY, 2016; QUINÁIA; FERREIRA, 2007).

\subsubsection{Titulação com N-bromosuccinimida}

A titulação com a $\mathrm{N}$-bromosuccinimida também pode ser utilizada e tem como princípio a oxidação do ácido ascórbico a dehidroascórbico pela N-bromosuccinimida. A amostra é estabilizada com solução de ácido tricloroacético e então iodeto de potássio, ácido acético e indicador de amido são adicionados. A titulação é realizada com N-bromosuccinimida. Assim que toda vitamina for oxidada, o excesso do reagente libera o iodo do iodeto de potássio, que é então detectado com o amido. O iodo é formado antes de outros compostos redutores reagirem com a N-bromosuccinimida (BALL, 1994).

O método pode ser aplicado em frutas e sucos de frutas, porém o ponto de viragem é de difícil detecção em produtos de leite e cereais. Assim, para situações nas quais o ponto final é mascarado, pode-se utilizar titulação 
potenciométrica. Em determinadas amostras, como tomates e limões pode ocorrer superestimação do teor de vitamina. Agentes redutores que interferem no método de Tillmans, como sais de ferro, não apresentam interferência na reação com a N-bromosuccinimida. Apenas compostos de enxofre se oxidam antes da liberação do iodo. Assim, a presença de sulfito, utilizado em conservantes como o metabissulfito em sucos e polpas, pode interferir. No entanto, o bissulfito pode ser complexado antes da titulação utilizando-se acetona (BALL, 1994).

\subsubsection{Titulação espectrofotométrica: Reação com o complexo $\left[\mathrm{Fe}(\mathrm{SCN})_{n}\right]^{(+3-n)}$}

Por fim, destaca-se a titulação espectrofotométrica, que consiste em um procedimento econômico e rápido otimizado por Quináia e Ferreira (2007) e que se baseia na decomposição do complexo $\left[\mathrm{Fe}(\mathrm{SCN})_{n}{ }^{(+3-n)}\right]$ para a determinação da vitamina em sucos de frutas e fármacos. O complexo é titulado com a amostra e o ácido ascórbico reduz o $\mathrm{Fe}^{3+}$ a $\mathrm{Fe}^{2+}$, prejudicando a sua ligação com o tiocianato e diminuindo a absorbância. As leituras são realizadas a $460 \mathrm{~nm}$ após cada adição de titulante e além do ponto de equivalência, que é determinado graficamente. A quantidade de reagentes e amostras utilizada é pequena e a técnica elimina determinados erros que podem acontecer em outros métodos titulométricos.

\subsubsection{Espectrofotométricos}

Os métodos espectrofotométricos se baseiam na capacidade das substâncias de absorver radiação eletromagnética na região do ultravioleta ou visível (BROWN et al., 2005; SPÍNOLA, 2011). São comuns os procedimentos para a determinação da vitamina que têm seu princípio a partir do caráter redutor do composto. Frequentemente utilizam-se indicadores do tipo redox, como metais, ou cromóforos (SPÍNOLA, 2011).

\subsubsection{Redução de íons cúpricos}

Dentre os métodos espectrofotométricos, a redução de íons cúpricos foi publicada por Contreras-Guzman, Strong III e Guernelli (1984) e se baseia na redução de íons cúpricos pela ação do ácido ascórbico com posterior complexação com cuproína. Para a extração da vitamina é utilizado ácido metafosfórico e, em um sistema bifásico com clorofórmio, é realizada a remoção de componentes com propriedades redutoras, como outras vitaminas, compostos terpênicos, taninos e demais substâncias lipossolúveis (SERON; CONTRERAS-GUZMÁN, 1993).

A fase aquosa contendo o ácido ascórbico e interferentes hidrossolúveis, como açúcares, pigmentos, entre outros, é tamponada com tampão de acetato de sódio, ácido acético e ureia ( $\mathrm{pH} 4,6)$ e agitada com uma fase orgânica na qual ocorre a reação, contendo álcool isoamílico, íons cúpricos e cuproína. O ácido 
ascórbico é oxidado a dehidroascórbico e os íons de cobre reduzidos formam um complexo de coloração púrpura com a cuproína, o $\left[\mathrm{Cu}\left(\text { cuproína) }{ }_{2}\right]^{+}\right.$, que é avaliado espectrofotometricamente a $545 \mathrm{~nm}$ (CONTRERAS-GUZMÁN; STRONG III; GUERNELLI, 1984; SERON; CONTRERAS-GUZMÁN, 1993). O sistema bifásico é útil para contornar a falta de especificidade dos íons cúpricos, já que interferentes permanecem em uma fase diferente daquela em que ocorre a reação (ALDRIGUE, 1998).

A metodologia é aplicável a alimentos naturais e industrializados, tendo sido testada pelos autores em frutas, hortaliças, produtos formulados, leites em pó, produtos de panificação e sucos de laranja. É interessante salientar que a técnica pode ser utilizada em amostras pigmentadas, que impedem a visualização do ponto final em métodos titulométricos. Além disso, ela pode ser aplicada em produtos que passaram por tratamentos térmicos e que eventualmente poderiam originar redutonas, que são compostos intermediários da reação de Maillard e interferem na quantificação da vitamina (CONTRERASGUZMÁN; STRONG III; GUERNELLI, 1984; IAL, 2008; SERON; CONTRERASGUZMÁN, 1993).

\subsubsection{Reação com 2,4-dinitrofenilhidrazina}

Outro método espectrofotométrico, utilizado por Roe e Kuther em 1943 para a determinação da vitamina $C$ total em sangue e urina, tem seu princípio a partir da reação do ácido dehidroascórbico com 2,4-dinitrofenilhidrazina $(\mathrm{DNFH})$ na presença de tioureia a $37^{\circ} \mathrm{C}$ por 3 horas. $\mathrm{O}$ ácido ascórbico é previamente oxidado a dehidroascórbico com carvão ativado na presença de ácido tricloroacético, utilizado na extração. Ao reagir com a DNFH, o ácido dehidroascórbico forma o bis 2,4-dinitrofenilhidrazona, uma osazona que ao ser tratada com ácido sulfúrico $85 \%$, origina um complexo de coloração vermelha. As reações estão representadas na Figura 3. A absorbância máxima se encontra entre 500 e $550 \mathrm{~nm}$, sendo $520 \mathrm{~nm}$ o comprimento mais comumente utilizado (ALDRIGUE, 1998; MUSSA; SHARAA, 2014; RIEMSCHNEIDER; MOCELLIN; ABEDIN, 1977; ROE; KUETHER, 1943; SPÍNOLA, 2011). 
Figura 3 - Oxidação ácido ascórbico seguida da reação com DNFH, tratamento ácido e formação de complexo

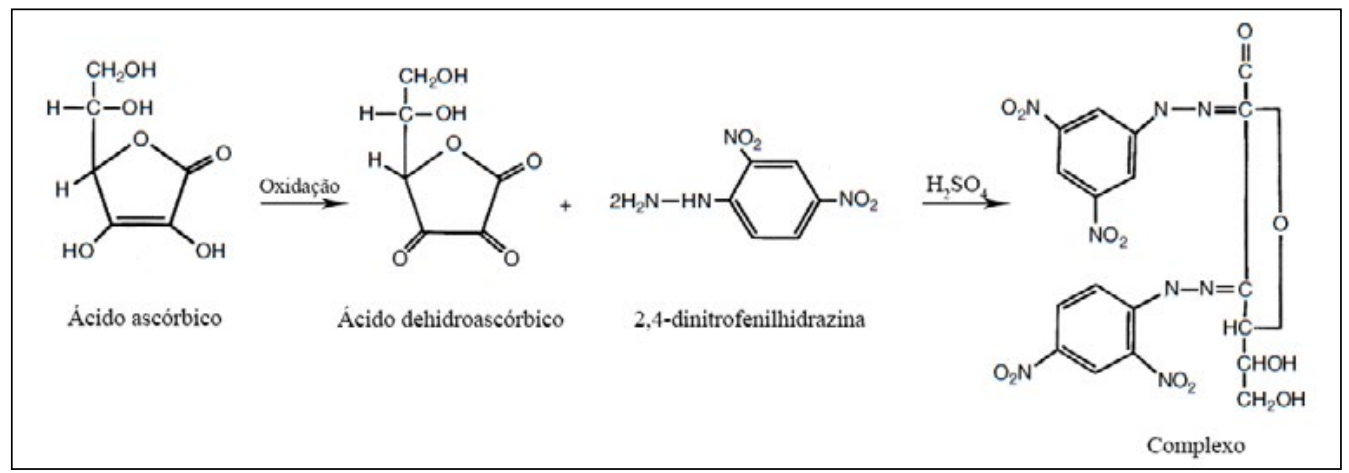

Fonte: Da autora, adaptado de Eitenmiller; Ye; Junior (2008).

O método é útil para a determinação de vitamina $C$ total se grandes quantidades de açúcar não estiverem presentes na amostra (EITENMILLER; YE; JUNIOR, 2008). Porém, as concentrações nas quais estes compostos interferem são significativamente maiores que as encontradas em amostras reais. E, caso o teor destas substâncias for muito elevado, as amostras podem ser diluídas, o que evita a interferência e ainda permite uma reação satisfatória (ROE; KUETHER, 1943). A especificidade da reação em matrizes complexas se dá pelo falo de a DNFH reagir mais rapidamente com o ácido dehidroascórbico em comparação a outros carboidratos e substâncias redutoras (EITENMILLER; YE; JUNIOR, 2008; SPÍNOLA, 2011).

Aldeídos e cetonas reagem com a DNFH, mas seus produtos de derivatização não apresentam reação com o ácido sulfúrico nas condições da análise e soluções do ácido com tais compostos não absorvem na região de leitura. A interferência de agentes oxidantes como $\mathrm{Fe}^{3+}$ e $\mathrm{H}_{2} \mathrm{O}_{2}$ é evitada com a utilização de tioureia na reação, que produz um meio redutor (ROE; KUETHER, 1943). Além disso, o uso do carvão ativado impede a interferência de pigmentos, já que estes ficam adsorvidos no material (BALL, 1994).

A técnica, com alterações, como o uso de água de bromo para realizar a oxidação do ácido ascórbico, foi empregada em demais estudos para a análise de vegetais, frutas e sucos de frutas, demonstrando ser simples e com resultados confiáveis. Nos trabalhos também foi checada a interferência de substâncias como glicose, frutose, sacarose e ácido dicetugulônico, porém, de acordo com os resultados, estas não afetaram a análise. O limite de detecção encontrado equivale a $0,01 \mathrm{ppm}$ e o limite de quantificação corresponde a 0,017 ppm (KAPUR et al., 2012; KHAN et al., 2006; MOHAMMED; HAMAD; MOHAMMED, 2009; MUSSA; SHARAA, 2014). 


\subsubsection{Complexação de ferro(II) com ácido picolínico}

A metodologia envolvendo a complexação de ferro(II) com o ácido picolínico foi desenvolvida por Arya e Mahajan (1996) e utilizada para a determinação de ácido ascórbico em produtos farmacêuticos, vegetais, frutas, sucos, leite e urina. A extração é realizada com ácido tricloroacético. O ácido ascórbico reduz o ferro(III) a ferro(II), que, na presença de piridina, forma um complexo de coloração amarelada com o ácido picolínico, sendo extraído em seguida com clorofórmio. $\mathrm{O}$ extrato resultante é analisado espectrofotometricamente a $400 \mathrm{~nm}$. A adição de piridina é essencial para a extração do complexo na fase orgânica, tornando-o mais hidrofóbico, e também para manter o $\mathrm{pH}$ desejado.

Dentre os interferentes avaliados, encontram-se os ânions $\mathrm{SO}_{3}{ }^{2-}, \mathrm{PO}_{4}{ }^{3-}$ e $\mathrm{S}_{2} \mathrm{O}_{3}{ }^{2-}$, que quando presentes em concentrações de miligramas acabaram provocando maiores alterações nos resultados. Demais vitaminas, aminoácidos, açúcares, compostos orgânicos, cátions e ânions testados apresentaram pouca ou nenhuma interferência. O método oferece simplicidade e rapidez, com desenvolvimento de cor instantâneo e estabilidade do complexo, sendo que sua extração para um meio orgânico previne a interferência de substâncias que apresentam coloração.

\subsubsection{Microextração líquido-líquido assistida por Vórtex}

Considerando a degradação do ácido ascórbico durante o processamento e armazenamento de alimentos, Bazel, Riabukhina e Tirpák (2018) ressaltam a importância da análise de traços da vitamina, que pode ser quantificada pela microextração líquido-líquido assistida por vórtex. Em muitas amostras, o teor do composto é inferior ao limite para sua quantificação em métodos espectrofotométricos, necessitando pré-concentração. A técnica desenvolvida se baseia na redução do ânion tri-iodeto $\left(\mathrm{I}_{3}^{-}\right)$na presença de corante de polimetina. $\mathrm{O}$ ácido ascórbico reage com o tri-iodeto gerando iodeto, que não forma par iônico com o corante. Nessa interação, ocorre a destruição do par iônico, o que provoca sua descoloração e consequente diminuição da absorção, ou seja, o método se baseia na redução da absorbância dos extratos.

A agitação dos componentes é realizada em Vórtex com tetraclorometano e na presença de tampão de acetato $(\mathrm{pH} 3,0)$ seguida de centrifugação. $\mathrm{O}$ triiodeto que não reagiu formado pelo par iônico é extraído para o solvente e avaliado espectrofotometricamente a $560 \mathrm{~nm}$. A determinação é realizada na fase orgânica devido ao sistema ser instável e coloidal.

O método pode ser utilizado em amostras de alimentos, sendo analisadas pelos autores frutas e cervejas. $\mathrm{O}$ limite de deteç̧ão corresponde a $0,89 \mu \mathrm{g} \mathrm{L}^{\mathrm{a} 1} \mathrm{e}$ o limite de quantificação é de $2,94 \mu \mathrm{g} \mathrm{L}^{\mathrm{a} 1}$. Interferentes encontrados consistem nos íons $\mathrm{NO}_{2}^{-}, \mathrm{BrO}_{3}^{-}, \mathrm{IO}_{3}^{-}, \mathrm{IO}_{4}^{-} \mathrm{e} \mathrm{Cr}_{2} \mathrm{O}_{7}^{2-}$, porém estes estão dificilmente presentes em produtos alimentícios. A metodologia foi comparada ao método 
de Tillmans, demonstrando ser mais sensível e prática quanto às características metrológicas. Também possui maior sensibilidade em relação à outras técnicas espectrofotométricas e a quantidade de solvente orgânico utilizado é muito pequena, equivalendo a $500 \mu \mathrm{L}$.

\subsubsection{Redução de selênio(IV) e cromo(VI)}

A redução de selênio(IV) e cromo(VI) são dois procedimentos viáveis para a análise de tabletes de vitamina, frutas e vegetais que foram desenvolvidos por Revanasiddappa e Veena (2008). No primeiro, a análise ocorre a partir da reação entre o ácido ascórbico com solução de selênio(IV) em meio acidificado com ácido clorídrico, seguida da adição de solução de iodeto de potássio e amido. A vitamina é oxidada e o selênio não reduzido, reage com iodeto liberando iodo, que forma o complexo com o amido. Com a diminuição da concentração de Se(IV), há menor absorção. Portanto, este método também é baseado na redução da absorbância, que decresce linearmente com o aumento do teor de ácido ascórbico. A máxima absorbância ocorre em $580 \mathrm{~nm}$. Os limites de detecção e quantificação são de 0,1570 e 0,4757 $\mu \mathrm{g} \cdot \mathrm{mL}^{-1}$ respectivamente.

$\mathrm{O}$ segundo procedimento tem seu princípio na oxidação da vitamina por excesso de $\mathrm{Cr}(\mathrm{VI})$ na presença de ácido sulfúrico. $\mathrm{O} \mathrm{Cr}(\mathrm{VI})$ não reduzido é determinado a partir da reação com a difenilcarbazida, formando um produto violeta avermelhado que é avaliado espectrofotometricamente a $550 \mathrm{~nm}$. Da mesma forma que o método anterior, ocorre diminuição da absorbância com o aumento do teor de ácido ascórbico. Os limites de detecção e quantificação equivalem respectivamente a 0,5784 e 0,8436 $\mu \mathrm{g} \cdot \mathrm{mL}^{-1}$.

Para ambas técnicas, não é necessária a extração da amostra, sendo utilizada apenas água destilada na sua preparação, o que aumenta a simplicidade. Não foram observadas interferências nas amostras analisadas. Os métodos são seletivos e possuem boa sensibilidade.

\subsubsection{Reação com auramina $O$}

Desenvolvido por Janghel, Sar e Pervez (2012), a reação com a auramina O foi empregada em sucos de frutas, vegetais, produtos farmacêuticos e amostras biológicas de sangue, leite e urina. Para a preparação das amostras, EDTA, ácido oxálico ou ácido tricloroacético são utilizados. Em alíquotas destas, são acrescentadas soluções de iodeto e iodato de potássio e ácido clorídrico, que, como já mencionado, levam à liberação de iodo, gerando coloração amarela. O corante auramina $\mathrm{O}$ é adicionado seguido de acetato de sódio ou hidróxido de sódio. $\mathrm{O}$ iodo produzido descolore o marrom do corante, diminuindo sua absorbância, que é avaliada a $405 \mathrm{~nm}$. Os limites de detecção e quantificação equivalem respectivamente a 0,0086 e $0,01 \mu \mathrm{g} \cdot \mathrm{mL}^{-1}$. Componentes comumente presentes em sucos de frutas e produtos farmacêuticos não interferiram. A interferência a partir de íons metálicos é evitada com a utilização de EDTA. 
O método é simples, apresenta boa sensibilidade, não requer extração em fase orgânica, possui baixo custo e a coloração desenvolvida tem alta estabilidade.

\subsubsection{Reação com o complexo $\mathrm{Cu}(\mathrm{II})-\mathrm{NH}_{3}$}

Já a reação com o complexo $\mathrm{Cu}(\mathrm{II})-\mathrm{NH}_{3}$ é indicada para a identificação da vitamina $\mathrm{C}$ em produtos farmacêuticos. A técnica realiza a preparação das amostras com água destilada ou ácido clorídrico. Estas são em seguida adicionadas em soluções do complexo $\mathrm{Cu}(\mathrm{II})-\mathrm{NH}_{3^{\prime}}$ ajustadas a $\mathrm{pH}$ 9,2 com hidróxido de sódio. $\mathrm{O}$ ácido ascórbico reduz o complexo a $\mathrm{Cu}(\mathrm{I})-\mathrm{NH}_{3}$, que possui menor absorbância e é instável, sendo que quando agitado e em contato com o ar, é oxidado novamente a $\mathrm{Cu}(\mathrm{II})-\mathrm{NH}_{3}$. Portanto, a absorbância deve ser avaliada imediatamente e sem mexer a amostra, e, desta forma, $\mathrm{o}_{2}$ não atua como interferente (FARAJZADEH; NAGIZADEH, 2003).

A diminuição da absorbância é proporcional ao teor de vitamina $C$. $0,026 \mathrm{mM}$ é o limite de detecção. As leituras espectrofotométricas são feitas a $600 \mathrm{~nm}$ e a coloração das amostras e vitaminas presentes não interferiu, devido ao comprimento de onda utilizado. Íons oxalato e citrato também foram estudados. $\mathrm{O}$ complexo $\mathrm{Cu}(\mathrm{II})$-citrato tem máxima absorbância apenas em $750 \mathrm{~nm}$ e o oxalato não reduz o cobre nas condições de análise. Excipientes de produtos comercializados também não alteraram os resultados. Portanto, o método pode ser utilizado como uma alternativa a iodimetria, por exemplo, que pode apresentar problemas em amostras coloridas. O procedimento é barato, não requer pré-tratamento de amostra e pode ser utilizado em análises de controle de rotina (FARAJZADEH; NAGIZADEH, 2003).

\subsubsection{Complexação de ferro(II) com fenantrolina}

Outro método se baseia na complexação de ferro(II) com a fenantrolina. Ao ser adicionada em solução acidificada com ácido clorídrico contendo $\mathrm{Fe}^{3+}$ e 1,10-fenantrolina (Phen), a vitamina $\mathrm{C}$ reduz o ferro a $\mathrm{Fe}^{2+}$, que forma um complexo de coloração laranja avermelhada com a fenantrolina, o Fe(Phen) ${ }_{3}^{2+}$, que é avaliado a $510 \mathrm{~nm}$. As amostras são preparadas a partir da dissolução em água. A técnica foi utilizada em suplementos, demonstrando ser simples, fácil, rápida e com baixo custo de reagentes (ADEM et al., 2016; DA SILVA et al., 2019).

O procedimento já foi descrito por Anwar et al. (1990) e foi empregado em fármacos. O complexo apresentou máxima absorbância em $515 \mathrm{~nm}$. Entre os íons estudados, a maior interferência é causada por sulfeto, sulfito e demais compostos capazes de reduzir o ferro, como a vitamina A. Nitrito e oxalato causam pouca interferência. 


\subsubsection{Correção de fundo através da oxidação do ácido ascórbico}

A análise direta por espectrofotometria UV do ácido ascórbico é rápida e simples, porém, a absorção da radiação UV pela matriz da amostra se torna um problema para tal procedimento. Para resolver isso, técnicas de correção de fundo foram desenvolvidas, nas quais realiza-se a oxidação do ácido L-ascórbico. A absorbância é avaliada primeiramente na amostra sem o agente oxidante e após na amostra na qual foi realizada a oxidação. O teor de ácido ascórbico pode ser calculado então a partir da diferença entre as absorbâncias encontradas (SALKIĆ; SELIMOVIĆ, 2015).

Salkić e Selimović (2015) elaboraram dois métodos que se baseiam na correção através da oxidação por peroximonossulfato de potássio e peróxido de hidrogênio na presença de $\mathrm{Cu}$ (II) como catalisador, aplicando-os em produtos farmacêuticos. No primeiro, é empregada solução estabilizadora contendoEDTA em tampão de ácido acético glacial e acetato de sódio $(\mathrm{pH} 6,0)$ na preparação da amostra. A oxidação do ácido ascórbico é realizada com peroximonossulfato de potássio, sendo a absorbância lida a $265 \mathrm{~nm}$. O ácido dehidroascórbico formado é insensível à radiação ultravioleta neste comprimento de onda. A utilização de estabilizador é necessária devido à instabilidade da vitamina em $\mathrm{pH}$ superior a 5,0. Os limites de detecção e quantificação são de respectivamente 0,19 e 0,65 $\mu \mathrm{g} . \mathrm{mL}^{-1}$.

No segundo método, para a preparação da amostra é utilizada solução tampão com os mesmos componentes, porém com pH de 4,50. A oxidação é realizada com peróxido de hidrogênio na presença de solução de $\mathrm{Cu}(\mathrm{II})$. A absorbância é avaliada a $262 \mathrm{~nm}$. Como a reação de oxidação neste meio ocorre muito lentamente, é necessária a utilização de cobre como catalisador, sendo então, descartado o uso de estabilizadores, pois podem formar complexo com o metal e retardar a reação. Os limites de deteç̧ão e quantificação equivalem a 0,15 e $0,51 \mu \mathrm{g} \cdot \mathrm{mL}^{-1}$ respectivamente.

Interferências devido a compostos usualmente presentes em produtos farmacêuticos foram estudadas. No primeiro método, apenas citrato e ácido cítrico, devido à mudança de $\mathrm{pH}$ que provocam, e nitrito, por causa da oxidação gerada em meio ácido no segundo procedimento, acarretaram em variação nos resultados. Porém, esta alteração se encontra na faixa aceitável definida e, portanto, tais compostos não foram considerados como interferentes. Ingredientes presentes nos produtos comerciais não interferiram. Os métodos apresentam boa sensibilidade, seletividade, os reagentes utilizados têm baixo custo e não é necessário pré-tratamento de amostra.

Fármacos também foram analisados por outra técnica, que emprega a solução estabilizadora composta por EDTA, tampão de ácido acético glacial e acetato de sódio $(\mathrm{pH} 4,10)$. Nitrito de sódio efetua a oxidação, que requer meio ácido, e a leitura da absorbância é feita a $256 \mathrm{~nm}$. Os limites de detecção e quantificação são de 0,12 e 0,41 $\mu \mathrm{g} \cdot \mathrm{cm}^{3}$ respectivamente. Devido à variação de 
pH causada pela presença de ácidos cítrico e lático e íons carbonato, bicarbonato, oxalato, acetato e citrato, houve pequena alteração nos resultados, no entanto, esta ficou dentro dos limites aceitáveis estabelecidos. Demais ânions, íons metálicos, açúcares e aminoácidos estudados, assim como excipientes presentes em amostras comerciais não apresentaram interferência. A técnica é simples, precisa, não requer extração e tem boa seletividade (SALKIĆ; KUBIČEK, 2008).

Para a análise de sucos de frutas, refrigerantes e licores, um método realiza a oxidação com sulfato de cobre(II) a $50{ }^{\circ} \mathrm{C}$, temperatura necessária devido à interferência de ácido cítrico, que está comumente presente nas amostras avaliadas e retarda a reação. Como o cobre absorve na faixa do ácido ascórbico, após a oxidação é adicionado EDTA, que forma um complexo com o metal que não absorve na região de leitura. O complexo não catalisa a oxidação à temperatura ambiente. A extração das amostras é realizada com solução de ácido metafosfórico e ácido acético e a absorbância é avaliada a $264 \mathrm{~nm}$ e com $\mathrm{pH}$ 6. Íons como $\mathrm{Al}(\mathrm{III}), \mathrm{Zn}(\mathrm{II}), \mathrm{Mg}(\mathrm{II})$ e $\mathrm{Fe}(\mathrm{II})$ geram erro negativo em consequência da catálise da oxidação da vitamina pelo ar. O método é seletivo e a maioria dos componentes usualmente presentes nas amostras analisadas não interferiram (ERWA; SHINGER; ISHAG, 2018; LAU; LUK; WONG, 1986; SALKIĆ; KUBIČEK, 2008).

\section{CONCLUSÃO}

São diversos os métodos desenvolvidos para a quantificação da vitamina $C$, portanto é essencial considerar o tipo de amostra a ser analisada, sua matriz, interferentes e demais características pertinentes. É importante conhecer as particularidades de cada procedimento, para assim escolher $\mathrm{o}$ mais adequado a fim de obter melhores resultados. Há uma grande variedade de amostras que podem ser analisadas, porém nem sempre o mesmo método é apropriado para os diferentes tipos. Para a análise de alimentos, bebidas e fármacos, ambos os procedimentos espectrofotométricos e titulométricos são utilizados, porém, os espectrofotométricos também possibilitam a quantificação da vitamina $\mathrm{C}$ em amostras biológicas. Todas técnicas apresentam vantagens e desvantagens e, apesar de novas serem desenvolvidas, as tradicionais são ainda bastante utilizadas, sendo indicadas até mesmo como metodologias oficiais ou empregadas na comparação de novos procedimentos. Embora as titulométricas e espectrofotométricas possam apresentar falta de especificidade ou interferentes em certos casos, tais problemas são evitados com a incorporação de determinadas etapas ou reagentes. Além disso, elas continuam a ser de grande interesse, devido ao baixo custo e praticidade que possuem, sendo inclusive adequadas para análises de rotina. 


\section{REFERÊNCIAS}

ADEM, Seid M.; LEUNG, Sam H.; ELLES, Lisa M. Sharpe; SHAVER, Lee Alan. A Laboratory Experiment for Rapid Determination of the Stability of Vitamin C. Journal of Chemical Education, v. 93, n. 10, p. 1766-1769, 2016. Disponível em: <https:/ / pubs. acs.org/doi/pdf/10.1021/acs.jchemed.6b00344>. Acesso em: 17 maio 2019.

ALDRIGUE, Mauro Luiz. Desenvolvimento e validação de metodologia analítica, utilizando a CLAE, para a determinação de vitamina $\mathrm{C}$ em frutas e seus principais produtos. 1998. 180 f. Tese (Doutorado em Ciências de Alimentos) - Faculdade de Engenharia de Alimentos, Campinas, São Paulo, dez. 1998. Disponível em: <http:/ / repositorio.unicamp.br/bitstream/REPOSIP/254288/1/Aldrigue_MauroLuiz_D. pdf >. Acesso em: 20 mar. 2019.

ANWAR, J.; FAROOQI, M. I.; NAGRA, S. A.; KHAN, A. M. A New Method for the Spectrophotometric Determination of Ascorbic Acid. Journal of The Chemical Society of Pakistan, v. 12, n. 1, 1990. Disponível em: <https:/ / www.jcsp.org.pk/ ArticleUpload/2876-13046-1-PB.pdf>. Acesso em: 17 maio 2019.

ARYA, Satya Prakash; MAHAJAN, Meenakshi. Spectrophotometric Determination of Ascorbic Acid Using an Iron(II)-Pyridine-Picolinic Acid Complex. Analytical Sciences, v. 12, dez. 1996. Disponível em: <https:/ /www.jstage.jst.go.jp/article/ analsci1985/12/6/12_6_941/_pdf/-char/en>. Acesso em: 2 abr. 2019.

ARYA, Satya Prakash; MAHAJAN, Meenakshi; JAIN, Preeti C. Nonspectrophotometric methods for the determination of Vitamin C. Analytica Chimica Acta, v. 417, p. 1-14, 2000. Disponível em: <https:/ / www.sciencedirect.com/science/ article/pii/S0003267000009090>. Acesso em: 18 mar. 2019.

. Photometric Methods for the determination of Vitamin C. Analytical

Sciences, v. 14, out. 1998. Disponível em: <https://www.jstage.jst.go.jp/article/ analsci/14/5/14_5_889/_pdf/-char/en>. Acesso em: 19 mar. 2019.

BALL, G. F. M. Water-soluble Vitamin Assays in Human Nutrition. 1 ed. Springer, 1994. E-book. Disponível em: <https://books.google.com.br/books/about/Water soluble_Vitamin_Assays_in_Human_Nu.html?id=TLwVAQAAMAAJ\&redir_esc=y $>$. Acesso em: 7 maio 2019.

BARCIA, Milene Teixeira; JACQUES, Andressa Carolina; PERTUZATTI, Paula Becker; ZAMBIAZI, Rui Carlos. Determinação de ácido ascórbico e tocoferóis em frutas por CLAE. Semina: Ciências Agrárias, Londrina, v. 31, n.2, p. 381-390, abr./jun. 2010. Disponível em: <https://www.redalyc.org/html/4457/445744096011/>. Acesso em: 2 abr. 2019.

BAZEL; Yaroslav; RIABUKHINA, Tetiana; TIRPÁL, Juraj. Spectrophotometric determination of ascorbic acid in foods with the use of vortex-assisted liquidliquid microextraction. Microchemical Journal, v. 143, p. 160-165, 2018. 
Disponível em: <https:/ /www.sciencedirect.com/science/article/pii/

S0026265X18307720?via\%3Dihub>. Acesso em: 13 abr. 2019.

BROWN, Theodore L.; JR. LEMAY, H. Eugene; BURSTEN, Bruce E.; BURDGE, Julia R. Química, a ciência central. 9. ed. São Paulo: Pearson Prentice Hall, 2005.

CONTRERAS-GUZMÁN, Emílio S.; STRONG III, Frederick C.; GUERNELLI, Ottílio. Determinação de ácido ascórbico (vitamina $\mathrm{C}$ ) por redução de íons cúpricos. Química Nova, v. 20, abr. 1984. Disponível em: <http:/ / quimicanova.sbq.org.br/detalhe_ artigo.asp?id=1615>. Acesso em: 18 mar. 2019.

CRUZ, R. A. N; LOBATO, L. P.; SANTOS, Sifuentes. Ácido ascórbico em preparados sólidos para refresco sabores limão e laranja. Scientia Plena, v. 9, n. 11, 2013. Disponível em: <https://www.scientiaplena.org.br/sp/article/view/1593/911>. Acesso em: 25 ago. 2018.

DA SILVA; Adélia Maria Lima; MARTINS, Bruno de Andrade; DEUS, Tatiana Nogueira. Avaliação do teor de ácido ascórbico em frutos do cerrado durante o amadurecimento e congelamento. Estudos, Goiânia, v. 36, n.11/12, p. 1159-1169, 2009. Disponível em: <http:/ / seer.pucgoias.edu.br/index.php/estudos/article/ view/484/825>. Acesso em: 1 set. 2018.

DA SILVA, Rodrigo Sens; PEDROSO, André Vinícius; DE JESUS, Paulo César; GELINSKI, Jane Mary Lafayette Neves; BORGES, Endler Marcel. Determinação de Vitamina C em Suplementos Alimentares Utilizando Métodos Volumétricos e Espectrofotometria de Absorção Molecular. Revista Virtual de Química, v. 11, n. 1, jan/fev. 2019. Disponível em: <http://rvq.sbq.org.br/imagebank/pdf/v11n1a12. pdf>. Acesso em: 8 maio 2019.

DAMODARAN, Srinivasan; PARKIN, Kirk L.; FENNEMA, Owen R. Química de alimentos de Fennema. 4 ed. Porto Alegre: Artmed, 2010.

DE ANDRADE, Ruth Sales Gama; DINIZ, Maria Celeste Teixeira; NEVES, Eduardo Almeida; NÓBREGA, Joaquim Araújo. Determinação e distribuição de ácido ascórbico em três frutos tropicais. Eclética Química, vol. 27, 2002. Disponível em: <http:/ / www.scielo.br/scielo.php?script=sci_arttext\&pid=S0100-46702002000200032>. Acesso em: 21 ago. 2018.

DE OLIVEIRA, Raquel Grando; GODOY, Helena Teixeira; PRADO, Marcelo Alexandre. Otimização de metodologia colorimétrica para a determinação de ácido ascórbico em geleias de frutas. Ciência e Tecnologia de Alimentos, Campinas, v. 30, n. 1, jan./mar. 2010. Disponível em: <http:/ / www.scielo.br/scielo.php?script=sci arttext\&pid=S0101-20612010000100036> . Acesso em: 21 mar. 2019.

EITENMILLER, Ronald R.; YE, Lin; JUNIOR, W. O. Landen. Vitamin analysis for the health and food sciences. 2 ed. 2008. E-book.

EL-ISHAQ, Abubakar; OBIRINAKEM, Simon. Effect of Temperature and Storage on Vitamin C Content in Fruit Juice. International. Journal of Chemical and 
Biomolecular Science, v. 1, n. 2, 2015. Disponível em: <https:/ / pdfs.semanticscholar. org/dada/15f9006dba0f8ec4c74cbc041de87b8863f1.pdf>. Acesso em: 17 ago. 2018.

ERWA, Ibrahum Yaagoub; SHINGER, Mahgoub Ibrahim; ISHAG, Omer Adam Omer. Background Correction Method for Determination of Ascorbic Acid in Baobab Fruit Pulp Using Direct UV Spectrophotometry. Chemical Science International Journal, v. 23, n. 2, 2018. Disponível em: <https:/ / www.researchgate.net/ publication/325662753_Background_Correction_Method_for_Determination_of_ Ascorbic_Acid_in_Baobab_Fruit_Pulp_Using_Direct_UV_Spectrophotometry $>$. Acesso em: 9 maio 2019.

FARAJZADEH, M. A.; NAGIZADEH, S. A Simple and Reliable Spectrophotometric Method for the Determination of Ascorbic Acid in Pharmaceutical Preparations. Journal of Analytical Chemistry, v. 58, n. 10, p. 927-932, 2003. Disponível em: <http:/ / web.b.ebscohost.com/ehost/pdfviewer/pdfviewer?vid=3\&sid=4a69ee52a82c-4dc8-99cb-6b9760c30a89\%40sessionmgr101>. Acesso em: 10 maio 2019.

FIORUCCI, Antonio Rogério; SOARES, Márlon Herbert Flora Barbosa; CAVALHEIRO, Éder Tadeu Gomes. A Importância da Vitamina C na Sociedade Através dos Tempos. Química Nova na Escola, n. 17, mai. 2003. Disponível em: <http:/ / qnesc.sbq.org.br/online/qnesc17/a02.pdf >. Acesso em: 21 set. 2018.

\section{INSTITUTO ADOLFO LUTZ - IAL. Métodos físico-químicos para análise de} alimentos. 4 ed. São Paulo: Instituto Adolfo Lutz, 2008. Disponível em: <http:/ /www. ial.sp.gov.br/resources/editorinplace/ial/2016_3_19/analisedealimentosial_2008. pdf>. Acesso em: 20 out. 2018.

JANGHEL, Etesh K.; SAR, Santosh; PERVEZ, Y. A new method for determination of ascorbic acid in fruit juices, pharmaceuticals and biological samples. Journal of Scientific \& Industrial Research, v. 71, p. 549-555, ago. 2012. Disponível em: <http:/ / nopr.niscair.res.in/bitstream/123456789/14525/1/JSIR \%2071\%288\%29\%20549-555. pdf $>$. Acesso em: 9 maio 2019.

KAPUR, A.; HASKOVIĆ, A.; ČOPRA-JANICIJEVIĆ, A.; KLEPO, L.; TOPČAGIĆ, A.; TAHIROVIĆ, I.; SOFIĆ, E. Spectrophotometric analysis of total ascorbic acid content in various fruits and vegetables. Bulletin of the Chemists and Technologists of Bosnia and Herzegovina, v. 38, 2012. Disponível em: <https:/ / www.researchgate. net/publication/268407682_Spectrophotometric_analysis_of_total_ascorbic_acid_ content_in_various_fruits_and_vegetables>. Acesso em: 20 mar. 2019.

KHAN, M. M. Rahman; RAHMAN; M. M.; ISLAM, M. S.; BEGUM, A. A. A simple UV-spectrophotometric method for the determination of vitamin $C$ content in various fruits and vegetables at Sylhet Area in Bangladesh. Journal of Biological Sciences, v. 6, n. 2, p. 388-392, 2006. Disponível em: <http:/ /docsdrive.com/pdfs/ansinet/ jbs/2006/388-392.pdf>. Acesso em: 20 mar. 2019.

LAU, Oi-Wan; LUK, Shiu-Fai; WONG, Kit-Sum. Background correction method for the determination of ascorbic acid in soft drinks, fruit juices and cordials using direct ultraviolet spectrophotometry. Analyst, v. 111, p. 665-670, 1986. 
Disponível em: <https://pubs.rsc.org/en/content/articlelanding/1986/AN/ AN9861100665\#!divAbstract>. Acesso em: 9 maio 2019.

LIMA, Eráclito Silva; DA SILVA, Elidiane Gomes; NETO, José Machado Moita; MOITA, Graziella Ciaramella. Redução da vitamina C em suco de caju (Anacardium occidentale L.) industrializado e cajuína. Química Nova, v. 30, n. 5, São Paulo, set./out. 2007. Disponível em: <http:/ / www.scielo.br/pdf/qn/v30n5/a17v30n5.pdf >. Acesso em: 17 mar. 2019.

MAJIDI, Mohammed Idaan Hassan AL; Y-ALQubury, Hazim. Determination of Vitamin C(ascorbic acid) Contents in various fruit and vegetable by UVspectrophotometry and titration methods. Journal of Chemical and Pharmaceutical Sciences, v. 9, n. 4, out./dez. 2016. Disponível em: <http://peptid.chem.elte.hu/files/ almajidi_1.pdf>. Acesso em: 10 maio 2019.

MOHAMMED, Qasim Y.; HAMAD, Wali M. MOHAMMED, Emad K. Specttrophotometric Determination of Total Vitamin C in Some Fruits and Vegetables at Koya Area - Kurdistan Region/Iraq. Journal of Kirkuk University - Scientific Studies, v. 4, n. 2, 2009. Disponível em: <https:/ /www.kujss.com/en/files/pdf/ vol4\%20no.2/39913.pdf>. Acesso em: 25 mar. 2019.

MUNYAKA, Ann W.; MAKULE, Edna E.; OEY, Indrawati; LOEY, Ann Van; HENDRICX, Marc. Thermal stability of L-Ascorbic acid and Ascorbic Acid Osidase in Broccoli (Brassica oleracea var. italica). Journal of Food Science, v. 75, n. 4, 2010. Disponível em: <https://www.researchgate.net/publication/44671621_Thermal_ Stability_of_L-Ascorbic_Acid_and_Ascorbic_Acid_Oxidase_in_Broccoli_Brassica_ oleracea_var_italica>. Acesso em: 21 ago. 2018.

MUSSA, Samira Ben; SHARAA Intisar El. Analysis of vitamin C (ascorbic acid) Contents packed fruit juice by UV-spectrophotometry and Redox Titration Methods. IOSR Journal of Applied Physics, v. 6, set./out. 2014. Disponível em: <http:/ / uob. edu.ly/assets / uploads/pagedownloads / d66b3-analysis-of-vitamin-c-ascorbic-acidcontents-packed-fruit-juice-by-uv-spectrophotometry-and-redox-titration-methods. pdf>. Acesso em: 28 mar. 2019

PENTEADO, Marilene de Vuono Camargo. Vitaminas: aspectos nutricionais, bioquímicos, clínicos e analíticos. 1 ed. São Paulo: Manole, 2003.

QUINÁIA, Sueli Pércio; FERREIRA, Márcia. Determinação de Ácido Ascórbico em Fármacos e Sucos de Frutas por Titulação Espectrofotométrica. Revista Ciências Exatas e Naturais, v. 9, n. 1, jan./jun. 2007. Disponível em: <https:/ / revistas. unicentro.br/index.php/RECEN/article/viewFile/27/106>. Acesso em: 30 abr. 2019.

REVANASIDDAPPA, H. D.; VENNA, M. A. Sensitive Spectrophotometric Methods for the Determination of Ascorbic Acid. E-Journal of Chemistry, v. 5, n. 1, p. 10-15, jan. 2008. Disponível em: <https:/ / www.researchgate.net/publication/258377333_ Sensitive_Spectrophotometric_Methods_for_the_Determination_of_Ascorbic_Acid $>$. Acesso em: 30 abr. 2019. 
RIEMSCHNEIDER, Randolph; MOCELLIN, Ruth Pereyron; ABEDIN, Mohamed Zainal. Determinação de vitamina C em batatas (Solanum tuberosum L.) submetidas a dois processos de industrialização. Revista Centro Ciências Rurais, v. 7, n. 3, 1977. Disponível em: <http:/ / coral.ufsm.br/revistaccr/index.php/RCCCR/article/ view/233/232>. Acesso em: 25 mar. 2019.

ROE, Joseph H.; KUETHER, Carl. The determination of ascorbic acid in whole blood and urine through the 2,4-dinitro-phenylhidrazine derivative of dehydroascorbic acid. Journal of Biological Chemistry, 1943. Disponível em: <http:/ /www.jbc.org/ content/147/2/399.full.pdf>. Acesso em: 24 mar. 2019.

ROSA Jeane Santos; GODOY, Ronoel Luiz de Oliveira; NETO, João Oiano; CAMPOS, Rodrigo da Silveira; DA MATTA, Virginia Martins; FREIRE, Cyntia Abreu; DA SILVA, Aline Soares; DE SOUZA, Rafael Santos. Desenvolvimento de um método de análise de vitamina $C$ em alimentos por cromatografia líquida de alta eficiência e exclusão iônica. Ciência e Tecnologia de Alimentos, Campinas, v. 27, n. 4, p. 837846, out./dez. 2007. Disponível em: <http://www.scielo.br/pdf/cta/v27n4/25.pdf>. Acesso em: 5 abr. 2019.

SALKIĆ, Mirsad; KUBIČEK; Ranka. Background Correction Method for the Determination of L-Ascorbic Acid in Pharmaceuticals Using Direct Ultraviolet Spectrophotometry. European Journal of Scientific Research, v. 23, n. 3, p. 351-360, 2008. Disponível em: <http:/ / 140904.showenter.com/image/users/140904/ftp/ my_files/Articles/Spectrophotometry/vit\%20C.pdf?id=9552829>. Acesso em: 5 maio 2019.

SALKIĆ, Mirsad; SELIMOVIĆ, Amra. Spectrophotometric Determination of L-Ascorbic Acid in Pharmaceuticals Based on Its Oxidation by Potassium Peroxymonosulfate and Hydrogen Peroxide. Croatica Chemica Acta, v. 88, n. 1, p. 7379, 2015. Disponível em: <https://hrcak.srce.hr/index.php?show=clanak\&id_clanak_ jezik=205143>. Acesso em: 5 maio 2019.

SERON, Lúcia Helena; CONTRERAS-GUZMÁN, Emílio S. Suco de laranja com ferro: aspectos químicos e nutricionais (uma alternativa no combate à anemia). Química Nova, v. 16, n. 1, 1993. Disponível em: <http:/ / quimicanova.sbq.org.br/imagebank/ pdf/Vol16No1_23_v16_n1_\%285\%29.pdf>. Acesso em: 25 mar. 2019.

SKOOG, Douglas A.; WEST, Donald M.; HOLLER, F. James; CROUCH, Stanley R. Fundamentos de química analítica. 9 ed. São Paulo: Cengage Learning, 2015.

SPÍNOLA, Vítor Agostinho Rodrigues. Novas metodologias para a determinação do conteúdo de ácido ascórbico em alimentos. 2011. 181 f. Dissertação (Mestrado em Bioquímica Aplicada) - Universidade da Madeira, Funchal, Portugal, 20 maio 2013. Disponível em: <https:/ / digituma.uma.pt/handle/10400.13/390>. Acesso em: 23 mar. 2019.

SUCUPIRA, Natália Rocha; XEREZ, Ana Caroline Pinheiro; SOUSA, Paulo Henrique Machado. Perdas vitamínicas durante o tratamento térmico de alimentos. Unopar científica. Ciências Biológicas e da Saúde, 2012. Disponível em: <http:/ / www. 
pgsskroton.com.br/seer/index.php/JHealthSci/article/viewFile/1025/984>. Acesso em: 18 ago. 2018.

TAVARES, José Torquato de Queiroz; SANTOS, Caio Márcio G.; DE CARVALHO, Laércio A.; DA SILVA, Cristiano Lôbo. Determinação volumétrica de ácido ascórbico pelos métodos de Tillmans e Balemtine. Magistra, Cruz das Almas, Bahia, v. 7, jan./dez., 1999. Disponível em: <https:/ / www.academia.edu/12417028/ DETERMINA\%C3\%87\%C3\%830_VOLUM\%C3\%89TRICA_DE_\%C3\%81CIDO_ ASC\%C3\%93RBICO_PELOS_M\%C3\%89TODOS_DE_TILMANS_E_BALEMTINE>. Acesso em: 18 mar. 2019.

VERMA, K. K.; JAIN, A.; SAHASRABUDDEY, B.; GUPTA, K.; MISHRA, Sanjeev. Solid-Phase Extraction Cleanup for Determining Ascorbic Acid and Dehydroascorbic Acid by Titration with 2,6-Dichlorophenolindophenol. Journal of AOAC International, v. 79, n. 5, p. 1236-1243, 1996. Disponível em: <https:/ /www. researchgate.net/publication/287604595_Solid-Phase_Extraction_Cleanup_for_ Determining_Ascorbic_Acid_and_Dehydroascorbic_Acid_by_Titration_with_26Dichlorophenolindophenol>. Acesso em: 17 maio 2019.

VILLELA, Gilberto G.; PECCI, José Danilo. Nota sobre a dosagem iodométrica da vitamina $\mathrm{C}$ nos frutos cítricos. Memórias do Instituto Oswaldo Cruz, v. 39, n. 3, 1943. Disponível em: <http:/ / www.scielo.br/scielo.php?pid=S007402761943000600004\&script=sci_abstract\&tlng=es>. Acesso em: 15 mar. 2019.

VOGEL, Arthur Israel. Análise química quantitativa. 6 ed. Rio de Janeiro: LTC, 2013. 